\title{
PRZENIKANIE POGAŃSKICH FORM KULTOWYCH DO CHRZEŚCIJAŃSTWA NA PRZYKŁADZIE KULTU BOGA ASKLEPIOSA I ŚWIĘTYCH ZWANYCH ANARGYROI
}

Zarówno dla pogan jak i chrześcijan doby późnego antyku cuda miały znaczenie podstawowe, stanowiąc najważniejszy wyznacznik wartości wyznawanej przez nich religii. Ani poganie, ani chrześcijanie nie wątpili nie tylko w realność, ale i w diaboliczność cudów strony przeciwnej. Diaboliczna proweniencja stanowiła bardzo dogodne wytłumaczenie podstaw działań taumaturgicznych przeciwników religijnych. Choć w apologiach kierowanych do pogan nacisk kładziono na boskie pochodzenie nauki chrześcijańskiej, akcentując Wcielenie Chrystusa, Jego dobrowolną śmierć i zmartwychwstanie, to argument $\mathrm{z}$ cudu był dla pogan niewiarygodny z uwagi na łatwość uznania go za magiczne działanie taumaturgiczne, zaś idea Boga cierpiącego i umierającego stanowiła centralny punkt teologii kultów misteryjnych ${ }^{1}$.

Za główną postać w polemice Sossianusa Hieroklesa i Euzebiusza z Cezarei, stanowiącej modelowy przykład sporu pogan i chrześcijan o ważność i oryginalność cudów, uznaje się obrosłego już w II w. po Chr. legendą boskiego męża Apolloniusza z Tiany, neopitagorejskiego świętego ${ }^{2}$. Uważa się, że pojęcie boskiego męża doby wczesnego cesarstwa rzymskiego, wybrańca bogów, nie jest łatwe do zdefiniowania, ponieważ obejmuje różne kategorie religijnych innowatorów, proroków i mędrców, nie sposób jednak nie zauważyć, że dominował w tym czasie model pitagorejski, udoskonalony przez neopitagoreizm, kreujący model „Pitagorasa nowych czasów”. Model ten kontynuowali póź-

${ }^{1}$ Por. R.M. Krill, Roman Paganism under the Antonines and Severans, ANRW II 16.1 (1978), ss. 27-44; M. Simon, Cywilizacja wczesnego chrześcijaństwa I-IV w., thum. E. Bąkowska, Warszawa 1979, s. 134 i nn.; ks. M. Rusecki, Cud w chrześcijaństwie, Lublin 1996, ss. 117-160; E. Wipszycka, Kościót w świecie późnego antyku, Warszawa 1994, s. 300-317.

${ }^{2}$ Hierokles wykpiwał łatwowierność chrześcijan, dla których wystarczającym dowodem boskości Chrystusa było dokonywanie przez Niego cudów. Apolloniusz z Tiany był jego zdaniem większym cudotwórcą niż Chrystus, a nikt z tego powodu nie uważał go za boga. W oczach Hieroklesa apostołowie Piotr i Paweł byli szarlatanami i prostakami, zaś sam Chrystus przywódcą bandy złoczyńców i magiem (Eusebius Caesariensis, Contra Hieroclem II). Euzebiusz z Cezarei skupił swój atak na biografii Apolloniusza autorstwa Filostrata. Tianejczyka, jego zdaniem, nie można uznać za byt boski, choć można za cnotliwego człowieka (ibidem IV, VII-IX). 
noantyczni, czy raczej późnohelleńscy boscy mężowie, najczęściej filozofowie neoplatońscy, stanowiąc niejednokrotnie poważną konkurencję dla świętych chrześcijańskich, by następnie ustąpić im miejsca ${ }^{3}$.

Legenda Apolloniusza jako taumaturga, uzdrowiciela i proroka wiązała się ściśle z kultem boga-lekarza Asklepiosa i czcią oddawaną mu w cylicyjskim mieście Ajgaj, które na początku V w. zaczęło być znane jako ośrodek kultowy św. Kosmy i Damiana, zaliczanych do grupy tzw. anargyroi (dosł. 'bez srebra', w sensie 'bez pieniędzy'), czyli świętych leczących za darmo. Jak wielkie zagrożenie dla chrześcijaństwa stanowił kult Asklepiosa, zbawcy uniwersalnego, stało się jasne już w II w. po Chrystusie. Niebezpieczeństwo to wynikało z ukazywanych w źródłach podobieństw postaci Asklepiosa i Chrystusa ${ }^{4}$. Celsus (ok. 135-254), platoński filozof z Aleksandrii, który swoje antychrześcijańskie dzieło Prawdziwe słowo wydał ok. 165 r., dopatrywał się wyższości Asklepiosa nad Chrystusem w możliwości bezpośredniego kontaktu z bogiem-lekarzem podczas inkubacji (lac. incubatio, gr. enkoimesis - 'ułożenie się do snu'), czyli pełniącego rolę objawienia snu w świątyni, dzięki któremu możliwe było powstanie i utrzymywanie osobistej więzi pomiędzy wiernymi a bóstwem ${ }^{5}$.

Niebezpieczeństwa dla chrześcijaństwa w kulcie Asklepiosa dopatrywało się wielu apologetów i pisarzy chrześcijańskich. Bardzo trudno było im znaleźć nie dające się zbić argumenty przeciw kultowi boga-lekarza ${ }^{6}$. Żyjący na przełomie III i IV w. Arnobiusz z Sikka, rozumiejąc trudności wynikające z podobieństwa postaci Asklepiosa i Chrystusa, nie odmawiał bogu-lekarzowi zdolności do uzdrawiania, a nawet wskrzeszania zmarłych, jednakże cudom jego przeciwstawiał cuda Chrystusa prowadzące do życia wiecznego, inaczej niż cuda Asklepiosa, przedłużające tylko życie ziemskie ${ }^{7}$. Chrystus poza tym leczył nie tylko dobrych, lecz także grzesznych, którym wybaczal, co nie było możliwe w kulcie Asklepiosa ze względu na bezwzględnie przestrzegany nakaz rytualnej czystości, pojmowanej także jako czystość duszy.

${ }^{3}$ Por. G. Fowden, The Pagan Holy Man in Late Antique Society, „Journal of Hellenic Studies” 102(1982) 33-59; M. Dzielska, Boscy mężowie, „Znak” 50(1998) nr 515, 41-54; eadem, Il „theios aner”, w: I Greci. Storia Cultura Arte Societa, vol. 2: Una Storia greca, p. III; Transformazioni, Torino 1998, ss. 1261-1280.

${ }^{4}$ Podobieństwo postaci Asklepiosa i Chrystusa musiało być popularne, skoro malarstwo katakumbowe i sceny na sarkofagach przedstawiają Chrystusa w himationie i sandałach, stroju greckich lekarzy, zaś samo wyobrażenie brodatego Chrystusa wywodzi się najprawdopodobniej od przedstawień Asklepiosa; por.: E. Thrämer, Asklepios, RE II 1662; D. Musiał, Asklepios - konkurent chrześcijaństwa?, w: Religie w świecie starożytnym, red. D. Musiał - M. Ziółkowski, Toruń 1993, s. 93.

${ }^{5}$ Por. Origenes, Contra Celsum III 3 i 24, SCh 136, 18 i 56, thum. S. Kalinkowski: Orygenes. Przeciw Celsusowi, Kraków 1986, ss. 142 i 152.

${ }^{6}$ Szerzej na ten temat por. R. Herzog, Asklepios, RACh 797-799; D. Musiał, Asklepios, 94; R. Dyrcz, Kult boga Asklepiosa w późnym antyku. (Na tle zmagań chrześcijaństwa z kultami pogańskimi) (w druku).

${ }^{7}$ Por. Adversus nationes I 48-49, CSEL 4, 32-33. 
Na rzymskim Wschodzie, gdzie kult Asklepiosa znany był przynajmniej od epoki hellenistycznej, i gdzie bóg-lekarz miał szczególnie wielu wyznawców, już za panowania Konstantyna Wielkiego (306-337) miały miejsce pierwsze otwarte wystąpienia przeciw kultom pogańskim, zaś jedną z pierwszych zburzonych świątyń starych bogów był asklepiejon w Ajgaj w Cylicji ${ }^{8}$. Niejasne jest jednak, dlaczego zburzono właśnie sanktuarium Asklepiosa, choć problem zdaje się wyjaśniać hipoteza łącząca zburzenie asklepiejonu w Ajgaj z próbą zlikwidowania ośrodka kultu Apolloniusza z Tiany, uznawanego za niebezpiecznego konkurenta Chrystusa ${ }^{9}$. Próba likwidacji kultu Asklepiosa w Ajgaj w 331 r. nie powiodła się w pełni. Jak wzmiankuje historyk bizantyjski Zonaras (XII w.), jeszcze w 363 r. cesarza Juliana Apostatę odwiedził w Tarsie kapłan Asklepiosa z Ajgaj, Artemiusz, prosząc go o pomoc w restauracji funkcjonującego mimo zniszczeń asklepiejonu ${ }^{10}$. Dopiero po śmierci Juliana nic nie mogło powstrzymać destrukcji świątyni boga-lekarza. Jej całkowite zniszczenie potwierdza retor Libaniusz w datowanej na 384/388 r. Mowie do cesarza Teodozjusza w obronie świątyń ${ }^{11}$.

Kult uniwersalnego zbawcy Asklepiosa przeszedł w ciągu V w. swego rodzaju transformację, zyskując szczególną popularność wśród filozofów neoplatońskich. Najbliżsi niewysłowionemu bogu neoplatoników byli przyjęci do ich nowego panteonu starzy bogowie oraz boscy mężowie - Sokrates, Pitagoras, Apulejusz z Madaury, Helios-Mitra, Asklepios i Apolloniusz z Tiany. Asklepiejony będące centrami intelektualnymi już od końca I w. po Chrystusie z czasem stały się ostojami pogaństwa i filozofii neoplatońskiej ${ }^{12}$.

Asklepiejon w Atenach, mimo edyktu Teodozjusza II z 435 roku, istniał jeszcze za życia najwybitniejszego późnoantycznego filozofa neoplatońskiego, Proklosa (ok. 410-485), który był również gorliwym czcicielem Asklepiosa ${ }^{13}$. Dom tego wielkiego kierownika Akademii znajdował się w pobliżu temenosu

${ }^{8}$ Por. Eusebius, Vita Constantini III 56, GCS 7, 103-104; Sozomenos, HE II 5, GCS 50, 57 , tłum. S. Kazikowski: Hermiasz Sozomenos, Historia Kościoła, Warszawa 1989, s. 91.

${ }^{9}$ Por. M. Dzielska, Apolloniusz z Tiany. Legenda i rzeczywistość, Kraków 1983, ss. 115 i nn.; R. Dyrcz, Wokót zburzenia przez. Konstantyna Wielkiego asklepiejonu w Ajgaj w Cylicji w 331 r. po Chr., „Nowy Filomata” 3(1999), 195-210.

${ }^{10}$ Por. Epitome historiarum XIII 12 C-D, ed. Dindorf, Leipzig 1870, III, s. 212.

11 Por. Oratio 30 (De templis), 39, tłum. L. Małunowiczówna: Libanios, Wybór mów, Wrocław 1953, s. 20.

12 Por. F. Graf, Heiligtum und Ritual. Das Beispiel der griechisch-römischen Asklepieia, w: Entretiens sur l'Antiquité Classique, t. XXXVII: Le Sanctuaire Grec IV, red. O. Reverdin B. Grange, Vandoeuvres-Géneve 1990, s. 199.

${ }^{13}$ Proklos czynnie uczestniczył w wielu kultach, oddając cześć Izydzie, Ozyrysowi, KybeleMatce Bogów, Marnasowi z Gazy, Theandritesowi oraz Asklepiosowi z Askalonu. W dzieciństwie wyleczył się z ciężkiej choroby dzięki interwencji Telesfora, syna Asklepiosa, zaś przez całe późniejsze życie pozostawał pod szczególną opieką Ateny, Pana i właśnie Asklepiosa, por. Dzielska, Boscy mężowie, s. 53. 
boga-lekarza, który sąsiadował z teatrem i świątynią Dionizosa na zboczu Akropolu. Likwidację ateńskiego asklepiejonu F.R. Trombley łączy z prześladowaniami pogan, które były konsekwencją buntu Illusa i wspieranej przez tego wodza uzurpacji Leoncjusza (484-488) ${ }^{14}$. Poważnym argumentem przeciw tej hipotezie jest jednak fakt, że chrześcijańska zabudowa na terenie temenosu Asklepiosa - kościół p.w. św. Andrzeja, powstała dopiero po likwidacji przez Justyniana Akademii w 529/532 roku ${ }^{15}$.

Marinos, biograf Proklosa, podczas trwania buntu Illusa w obawie przed prześladowaniami uciekł z Aten do Epidauros, gdzie jak zapisał Damascjusz, mógł żyć bez obaw o własny $\operatorname{los}^{16}$. Wzmianka ta dowodzi, że również asklepiejon epidauryjski istniał jeszcze w 2. poł. V wieku, spełniając rolę azylu dla prześladowanych pogan. Wzmianki u Marinosa i Damascjusza są ostatnimi literackimi świadectwami istnienia i działania asklepiejonów w Atenach i Epidauros.

Pochodząca z VI w. relacja o misyjnej działalności biskupa Jana z Efezu, nie wspomina o trwaniu kultu Asklepiosa we Frygii, Karii i Lidii, choć ze źródeł literackich wiadomo, że na terenie prowincji małoazjatyckich znajdowało się jeszcze osiem znanych sanktuariów Asklepiosa ${ }^{17}$. Trudno to jednakże uznać za dowód ex silentio na ostateczne pokonanie przez chrześcijaństwo kultu Asklepiosa w ciągu VI wieku. Niewątpliwie ostateczne pokonanie kultu boga-lekarza nastąpić mogło dzięki wchłonięciu przez chrześcijaństwo inkubacyjnej metody leczenia, którą z powodzeniem stosowano w lecznictwie uprawianym w kościołach pod wezwaniem bardzo wielu świętych chrześcijańskich. Ważnym czynnikiem była tu niewątpliwie tzw. „ciągłość psychologiczna” - wzbudzające niegdyś wiele kontrowersji pojęcie, tłumaczące zjawisko łatwego przechodzenia pogan na chrześcijaństwo, wprowadzone do nauki przez T. Zielińskiego ${ }^{18}$.

$\mathrm{Na}$ Zachodzie inkubacyjne kulty świętych koncentrowały się głównie na obszarach Brytanii, Galii i Italii ${ }^{19}$. Na terenie Galii, a później średniowiecznej Francji, inkubacyjna metoda leczenia poświadczona została przez Wenancjusza Fortunata w kościele nad grobem św. Medarda, biskupa Suessionum (Sois-

14 Por. F.R. Trombley, Hellenic Religion and Chrystianisation (370-529), t. 1, Leiden 1993, ss. $311,342 \mathrm{i} \mathrm{nn}$.

15 Por. A. Franz, From Paganism to Christianity in the Temples of Athens, „Dumbarton Oaks Papers" 19(1965), ss. 193 i n.

${ }^{16}$ Por. Damascius, Vita Isidori, fr. 266, ed. Zintzen s. 213; Damascjusz był Diadochem Akademii od 526 roku do jej zamknięcia w 529/532 roku.

${ }^{17}$ Por. Edelstein, Asclepius. A Collection and Interpretation of the Testimonies, Baltimore 1945, t. I, ss. 405-422; na temat działalności misyjnej Jana z Efezu zob. M. Whitby, John of Ephesus and the Pagans: Pagan Survivals in the Sixth Century, w: Byzantina et Slavica Cracoviensia, I, Paganism in the Later Roman Empire and in Byzantium, ed. by M. Salamon, Cracow 1991, ss. 111-131.

${ }_{18}$ Por. T. Zieliński, Elementy wschodnie w religiach świata antycznego, Warszawa 1938, s. 459.

19 Por. L. Deubner, De incubatione christiana capita quattuor, Lipsiae 1900, s. 62. 
sons $)^{20} ; z$ cudownych uzdrowień podczas inkubacji słynęło też sanktuarium św. Eligiusza w Noviomagum (Noyon) $)^{21}$. Z identycznych metod leczniczych i cudownych uzdrowień słynęło sanktuarium św. Juliana w Turonorum (Turenne $)^{22}$, mieście św. Marcina. Znany jest przypadek zastosowania inkubacji w Saint-Denis pod Paryżem ${ }^{23}$. Z leczniczych porad, udzielanych we śnie, słynął także św. Maksymin z Trewiru, o którym wiadomo, że zmarł ok. 349 roku, a biskupem miasta był już za czasów panowania Konstantyna Wielkiego ${ }^{24}$. O inkubacji, której arcybiskup Laurencjusz poddał się w portyku św. Marcina wewnątrz sanktuarium św. Piotra i Pawła w Cantabrigium (Cambridge), donosi natomiast Beda Czcigodny ${ }^{25}$.

Niezwykle interesujący jest fakt, że ilość wzmianek dotyczących stosowania inkubacji w sanktuariach chrześcijańskich, a więc popularności tej metody leczniczej, jest właściwie wprost proporcjonalna do ilości świadectw dotyczących kultu Asklepiosa w odpowiednich prowincjach rzymskich. Na terenie rzymskiej Brytanii znaleziono zaledwie pięć inskrypcji zawierających dedykacje dla boga-lekarza, co stanowi zaledwie znikomą część inskrypcji sakralnych pochodzących z wyspy. W Brytanii czczono wiele bóstw uzdrowicielskich, lecz to Apollo, a nie Asklepios był z nimi utożsamiany ${ }^{26}$. Inkubacyjne metody lecznicze mogły być znane w innych kultach uzdrowicielskich, szczególnie pochodzenia galijskiego, nie obcych przecież mieszkańcom wyspy.

Analogiczna sytuacja wytworzyła się w Galii. Nie związany z kultem Asklepiosa rytuał inkubacji pojawił się w galijskich kultach źródeł jeszcze przed podbojem rzymskim. $Z$ terenu Galii (Riez) znana jest niezwykle znamienna inskrypcja, z której wynika, że niejaki Valerius Symphorus z żoną ofiarowali Asklepiosowi srebrny torques ozdobiony symbolicznymi przedstawieniami świętych zwierząt boga-lekarza - dwoma złotymi wężami; srebrny lancet, kleszcze chirurgiczne oraz posążek snu ${ }^{27}$. Obecność tego właśnie posążka świadczy o praktykowaniu w Galii rytuału inkubacji. Faktem jest jednak, że nie są znane żadne świadectwa dotyczące kultu boga-lekarza w galijskich miejscowościach słynących ze źródeł leczniczych. Podobnie jak w Brytanii, najlepiej za-

${ }^{20}$ Por. Venantius Fortunatus, Carmina II 16, 143 (De S. Medardo), MGHaa IV 1, 48.

${ }^{21}$ Por. Vita S. Eligii II 51, MGHMer IV 729.

${ }^{22}$ Por. Liber de virtutibus Juliani 47, MGHMer I 2, 583.

${ }^{23}$ Por. Deubner, De incubatione christiana, s. 58, przyp. 1; na temat kultu św. Dionizego w Paryżu zob. G.M. Spiegel, The Cult of St Denis and Capetian Kingship, w: Saints and their Cults. Studies in Religious Sociology, Folklore and History, ed. by S. Wilson, Cambridge 1983, ss. 141-168.

${ }^{24}$ Por. Deubner, De incubatione christiana, s. 59 i nn.

${ }^{25}$ Por. Beda Venerabilis, Historia Ecclesiastica Gentis Anglorum II 6, PL 95, 91A; Deubner, De incubatione christiana, s. 58.

${ }^{26}$ Por. D. Musiał, Le développement du culte d'Esculape au monde romain, Toruń 1992, s. $77 \mathrm{i}$ nn.

27 Por. Corpus Inscriptionum Latinarum XIII 354. 
symilowanym bóstwem leczniczym w Galii był Apollon, który pełnił tam funkcje należące w świecie greckim do Asklepiosa ${ }^{28}$.

Również w Italii ten jeden z najpopularniejszych bogów greckiego świata spotkał się ze swego rodzaju obojętnością miejscowej ludności, której bliższe były lokalne bóstwa uzdrowicielskie. Nie można jednakże mówić o odrzuceniu kultu Asklepiosa. Bóg-lekarz przegrał rywalizację z Apollonem przede wszystkim w Italii północnej, pozostającej pod silnym wpływem wierzeń celtyckich. W Italii środkowej i północnej znajdowało się stosunkowo niewiele świątyń poświęconych Asklepiosowi, mimo że tylko w dolinie Padu istniało 70 ośrodków kultowych różnych bóstw leczniczych. Znane są zaledwie trzy asklepiejony italskie: sanktuarium na Insula Tiberina (Inter duos Pontes) w Rzymie, świątynia w Ancjum, oraz - wzorowana w swoim układzie architektonicznym na sanktuarium na Kos - świątynia we Fregellae ${ }^{29}$.

Niezwykle interesujące jest to, że Asklepios był jednym z najpopularniejszych bóstw czczonych przez zamieszkujących południową Italię Greków. Upowszechnienie jego kultu na Sycylii wiązało się z polityczną obecnością Aten na tym terenie w 2. poł. V w. przed Chrystusem, choć w samych Atenach do panteonu bóstw państwowych włączony został dopiero na pocz. IV w. przed Chrystusem. Asklepios był bóstwem niezwykle popularnym także na Sardynii, co wiązało się $\mathrm{z}$ identyfikowaniem go na wyspie $\mathrm{z}$ fenickim Eshmunem. O znaczeniu kultu Asklepiosa na terenie Wielkiej Grecji świadczy jednak najlepiej datowana na ok. 350 r. przed Chrystusem lista przedstawicieli sanktuarium epidauryjskiego w większości miast tego rejonu ${ }^{30}$. Popularność związanego z inkubacją kultu Asklepiosa w Italii południowej utrzymywała się całe wieki, o czym świadczy wielka ilość materiałów inskrypcyjnych pochodzących z okresu cesarstwa ${ }^{31}$.

L. Deubner zauważył, że inkubacja jako metoda lecznicza była bardzo rozpowszechniona w Kościele italskim, szczególnie na terenie Kalabrii. Inkubację stosowano również w kościele p.w. św. Antoniego w Padwie ${ }^{32}$. E. Rohde zwrócił uwagę na fakt, że inkubacyjny kult Kalchasa w Apulii został w zdumiewająco prosty sposób zastąpiony przez kult św. Michała Archanioła. W V wieku w pieczarze na apulijskiej górze Garganus, będącej centralną częścią wyroczni herosów Kalchasa i Podalejriosa, syna Asklepiosa, dwukrotnie ukazał się św. Wawrzyńcowi Maiorano sam Archanioł Michał. Wydarzenie to spowodowało, że zaczęto mu w tym miejscu oddawać szczególną cześć, wybudowano kościół i klasztor, a antyczny Mons Garganus przemianowano na

28 Por. Musiał, Le développement du culte, ss. 79-82.

${ }^{29}$ Por. Graf, Heiligtum und Ritual, ss. 160-167; Musial, Le développement du culte, ss. 28-46; 60-71.

${ }^{30}$ Por. Inscriptiones Graecae IV 95.

${ }^{31}$ Por. Musiał, Le développement du culte, ss. 10 i nn.; 60-67.

32 Por. Deubner, De incubatione christiana, s. 61. 
Monte Sant' Angelo ${ }^{33}$. Regionem, w którym kult Michała Archanioła był wyjątkowo rozpowszechniony, była Frygia. Archanioł ten zażywał tam specjalnej czci już w III wieku. O popularności św. Michała Archanioła we Frygii świadczy najlepiej fakt, że 35 kanon synodu w Laodycei, gdzie obradowali przede wszystkim biskupi Frygii i Pizydii, przyznał mu naczelne miejsce w hierarchii anielskiej. Miejscem zaś we Frygii, gdzie zażywał szczególnej czci, było źródło w Chaeretopa, pomiędzy Kolossami i Hierapolis, miastami bardzo często umieszczającymi na bitych w nich monetach portrety bądź symbole Asklepiosa i Hygiei. Uzdrowicielskiej mocy Archanioła doświadczało się tam zanurzając chorą część ciała w wodzie źródła. Z uzdrowicielskiego źródła słynęło także miasto Chonae, w pobliżu którego zdrój tryskał ze skalnej szczeliny, według legendy, dzieła samego św. Michała Archanioła. Innym małoazjatyckim ważnym ośrodkiem kultowym św. Michała Archanioła było sanktuarium w Pythii w Bitynii, znane z leczniczych źródeł i doskonałego szpitala, fundacji cesarza Justyniana. Cesarz ten ufundował również szpital św. Michała w Perge w Pamfylii ${ }^{34}$. Inkubację znano i praktykowano w kościele św. Michała Archanioła w Konstantynopolu, w tzw. Michaelion, dawnej świątyni nazywanej Sosthenion, której założenie wiązano $\mathrm{z}$ wyprawą Argonautów. Poświęcenie tego miejsca Michałowi Archaniołowi wiązano z decyzją samego Konstantyna Wielkiego, któremu miał się on objawić we śnie. E. Lucius założył, że sam cesarz poddał się najprawdopodobniej inkubacji, a mogło to mieć miejsce w Sosthenion lub raczej w konstantynopolitańskiej świątyni Serapisa ${ }^{35}$.

Inkubacja jako ryt o charakterze kultowym i leczniczym zarazem, znana i praktykowana była przede wszystkim w kulcie świętych zwanych anargyroi. Grupę świętych określanych tym mianem tworzą postacie męczenników, których kult rozwinął się i kwitł w starożytności głównie na Wschodzie. Do najważniejszych z nich należą św. Tekla ${ }^{36}$, święci Cyrus i Jan ${ }^{37}$ oraz święci Kosma i Damian.

Kosma i Damian byli braćmi i lekarzami praktykującymi w Ajgaj w Cylicji. Pochodzili z Arabii, a sztuki lekarskiej uczyli sie w Syrii. Lecząc w Ajgaj nawracali pogan. Kiedy wybuchły prześladowania za Dioklecjana jako jedni z pierwszych zostali na rozkaz prefekta Lysiasa aresztowani i po osądzeniu ścięci wraz z trzema swoimi braćmi - Anthimosem, Leontiosem i Euprepiosem. Ich kult, początkowo o lokalnym jedynie znaczeniu, rozwinął się szcze-

${ }^{33}$ Por. E. Rohde, Psyche, Tübingen 1907, s. 186, przyp. 2.

${ }^{34}$ Por. E. Lucius, Die Anfänge des Heiligenkults in der christlichen Kirche, Tübingen 1904, s. $267 \mathrm{i} \mathrm{n}$.

35 Ibidem, ss. $268 \mathrm{i} \mathrm{nn.}$

${ }^{36}$ Ibidem, ss. 205-214; Deubner, De incubatione christiana, ss. 98-103.

${ }^{37}$ Por. R. Herzog, Der Kampf um den Kult von Menuthis, w: Pisciculi. Festschrift F.J. Dölger, München 1939, ss. 117-124; Deubner, De incubatione christiana, ss. 80-98; Lucius, Die Anfänge des Heiligenkults, ss. 262-266. 
gólnie po soborze w Efezie (431). Zachowało się 48 opisów cudownych uzdrowień dokonanych przez tych świętych ${ }^{38}$.

Hipotezę, że świętych Kosmę i Damiana postrzegać należy jako chrześcijańskich następców kultu Asklepiosa, postawił E. Lucius, posługując się przykładem Ajgaj, najpierw ważnego ośrodka kultowego Asklepiosa, później zaś św. Kosmy i Damiana ${ }^{39}$. Hipotezę Luciusa ostro zwalczał Deubner argumentując, że Ajgaj nie było miejscem kaźni świętych, ponieważ, jego zdaniem, niemożliwe było, aby rozkwitający dopiero po soborze w Efezie (431) kult męczenników mógł trwać w swego rodzaju uśpieniu od czasów Dioklecjana, oraz że Acta Martyrum łączące kaźń z prefektem Lysiasem i Ajgaj zostały dopiero sfabrykowane w późniejszym okresie. Zdaniem Deubnera za autentyczne uznać można jedynie tzw. martyrium rzymskie, co prowadzi do założenia, że męczeństwo św. Kosmy i Damiana miało miejsce w okresie panowania Karynusa (282-283) oraz że kult św. Kosmy i Damiana wywodzić należy raczej od Dioskurów, czy Podalejriosa i Machaona niż od Asklepiosa, ponieważ kult dwóch świętych nie mógł zastąpić kultu pojedynczego bóstwa ${ }^{40}$. Argumentacja Deubnera wydaje się być w pewnych szczegółach nie pozbawiona wad. Połączenie kultu św. Kosmy i Damiana z Ajgaj tłumaczy ostrość wystąpień przeciw tamtejszemu asklepiejonowi. Męczeństwo świętych poprzedza o ok. 36 lat zburzenie asklepiejonu, to zaś okres, jak się wydaje, wystarczająco długi, by mógł się narodzić kult męczenników. Natomiast argument dotyczący upatrywania prototypów kultu św. Kosmy i Damiana w pogańskich boskich parach, zamiast w kulcie jednego bóstwa, wzmacnia tylko hipotezę, że asklepiejon w Ajgaj był sanktuarium nie tylko boga-lekarza, ale i jego kapłana, boskiego męża, Apolloniusza z Tiany ${ }^{41}$.

Łatwa zamiana inkubacyjnych kultów pogańskich na kulty chrześcijańskich świętych ukazuje nam wyraźnie charakterystyczny rys mentalności ludzi doby późnego antyku - głód cudów, czy też raczej swego rodzaju świętej cudowności. Zdumiewa fakt, że przenikały do chrześcijaństwa nie tylko formy kultowe, lecz również architekturę niektórych sanktuariów chrześcijańskich świętych wzorowano na układzie architektonicznym asklepiejonów. Wszystkie zaś asklepiejony wykazywały w szczegółach lokalizacji i założeniu przestrzennym pewne wspólne cechy. Zakładano je na peryferiach miast lub poza ich granicami, w miejscach porośniętych drzewami, obfitujących w źródła mineralne i o dobrych warunkach klimatycznych ${ }^{42}$. Założenie architektoniczne sanktuarium

38 Podstawową pracą dotyczącą kultu św. Kosmy i Damiana w starożytności jest: L. Deubner, Kosmas und Damian. Texte und Einleitung, Leipzig 1907.

39 Por. Lucius, Die Anfänge des Heiligenkults, ss. 256-260.

40 Por. Deubner, De incubatione christiana, ss. 38-83.

41 Por. przyp. 11.

42 Por. Graf, Heiligtum und Ritual, ss. 168-186, 198 i n.; D. Musiał, Asklepiejony jako ośrodki opieki nad chorymi w starożytności, VoxP 16(1996) z. 30-31, s. 63. 
św. Cyrusa i Jana w Menuthis uderzająco przypominało asklepiejon - centralnie usytuowany kościół, przed którym znajdował się służący do ablucji zbiornik wodny, otaczały budynki służące jako hospicja, zaś inkubacja odbywała się w jednej z naw kościoła lub w portykach otaczających dziedziniec ${ }^{43}$. Najbardziej zdumiewające jest jednak to, że opisy uzdrowicielskich cudów anargyroi dają się porównać ze spisanymi w IV w. przed Chrystusem w Epidauros cudownymi uzdrowieniami Asklepiosa. Zarówno cuda Asklepiosa jak i świętych chrześcijańskich podzielić można na trzy grupy: przypadki pozytywne - błagalnik otrzymuje to o co prosił, przypadki negatywne - ukaranie niedowiarka, cuda prowadzące do nawrócenia.

Grupa pierwsza jest we wszystkich zbiorach cudów najliczniejsza. Ze względu na rodzaj wyleczonego schorzenia, czy zastosowane środki daje się ona podzielić na mniejsze podgrupy. Oto kilka bardziej charakterystycznych przykładów dotyczących uleczeń z chorób oczu, których dokonali chrześcijańscy święci i pogański bóg. Jeden z cudów Asklepiosa opowiada o cudownym uzdrowieniu nieznanego $z$ imienia człowieka bez oka poprzez wlanie w jego oczodół bliżej nieokreślonego leku ${ }^{44}$. Natomiast ślepy na jedno oko Alkestas odzyskał w cudowny sposób wzrok, gdy po złożeniu ofiary ślubował bogu jeszcze większą obiatę, a nawet to, że w ciągu roku wpłaci jedną minę srebra do skarbca świątynnego ${ }^{45}$. Hermon $z$ Thasos, który mimo iż bóg uleczył go ze ślepoty nie złożył obiecanego wotum, został dotknięty ślepotą powtórnie. Kiedy zrozumiał swój błąd i złożył ofiarę, Asklepios wybaczył mu i ponownie uzdrowił podczas inkubacji ${ }^{46}$.

Podobnie dzieje się w cudach św. Cyrusa i Jana - pewien heretyk został uzdrowiony przez świętych, kiedy jednak po powrocie do domu nie rozstał się z herezją, której się poprzednio wyrzekł, święci pozbawili go za to wzroku. Wówczas przyrzekł nawrócenie na prawdziwą wiarę i został ponownie uzdrowiony ${ }^{47}$. Mężczyzna mający bielmo na oczach uleczony zostaje przez świętych po wykonaniu polecenia otrzymanego podczas inkubacji, polegającego na przemyciu oczu w źródle i przetarciu ich chustą, na którą w efekcie bielmo przeszło $^{48}$. O bardzo podobnej sytuacji opowiada jeden z cudów Asklepiosa, gdzie mowa jest o przeniesieniu piętna $z$ czoła człowieka na opaskę ${ }^{49}$.

${ }^{43}$ Por. Wipszycka, Kościót w świecie późnego antyku, s. 307.

${ }^{44}$ Por. Miracula Aesculapii 9, ed. Herzog (1931); bardzo dziwną kurację lekową zalecili św. Kosma i Damian - chory mężczyzna odzyskał wzrok po zwilżeniu oczu mlekiem wiernej żony, zob. Miracula SS. Cosmae et Damiani 25, ed. Deubner (1907).

${ }^{45}$ Por. Miracula Aesculapii 69.

46 Ibidem 22.

${ }^{47}$ Por. Miracula SS. Cyri et Johannis 38, ed. Mai (1840).

48 Ibidem 2.

${ }^{49}$ Por. Miracula Aesculapii 6. 
Jeden z cudów św. Tekli dotyczy wyleczenia dziecka ze zropiałym okiem. Cud miał miejsce w gaju świętej na terenie sanktuarium w Seleucji. Żuraw, z którym bawiło się chore dziecko, dziobnął je w oko, co spowodowało, ze wypłynęła zasłaniająca źrenicę gęsta ropa ${ }^{50}$. Łatwo przytoczyć analogiczny cud Asklepiosa - nieznany z imienia mężczyzna z Chios wyleczony został z podagry przez gęś, która podczas snu podziobała do krwi jego nogi ${ }^{51}$.

Z opisów wielu cudów dowiadujemy się, że przyczyną chorób były pasożyty w jamie brzusznej oraz połknięte zwierzęta. Sostrata z Ferai cierpiała na tak zaawansowaną robaczycę, że do portyku inkubacyjnego musiano ją wnieść. Tam nie miała wyraźnego widzenia. $W$ drodze powrotnej do domu, w okolicach Kornoi, nieznany przystojny mężczyzna zoperował ją i wyjął z jej brzucha tyle robaków, że zapełniły one dwie pełne misy. Po operacji Asklepios dał jej się poznać i polecił jej posłać do Epidauros ofiarę za wyleczenie ${ }^{52}$. Erasippę z Kaphyiai cierpiącą na robaczycę, powodującą obrzęk całego ciała i złośliwą obstrukcję, Asklepios uleczył podczas inkubacji pocałunkiem, podaniem blizej nieokreślonego płynnego lekarstwa i sprowokowaniem wymiotó $w^{53}$. O podobnym przypadku opowiada jeden z cudów św. Cyrusa i Jana: niejaka Teodora przez nieostrożność połknęła małą żabę, która w jej brzuchu urosła i stała się przyczyną poważnych dolegliwości. Święci polecili jej napić się na czczo wody, co spowodowało, że zwymiotowała połknięte przypadkowo zwierzę $e^{54}$.

Poczesne miejsce w zbiorach miraculów zajmują przypadki negatywne, czyli cuda karzące niedowiarków i krzywoprzysiężców, oraz cuda prowadzące do nawrócenia. Mężczyzna z częściowym paraliżem dłoni został uzdrowiony przez Asklepiosa za pomocą masażu, polegającego na skakaniu po jego dłoni; ponieważ ów chory nie wierzył początkowo w prawdziwość cudownych opisów uzdrowień w Epidauros, warunkiem leczenia było również przybranie imienia "Niedowiarek" "55. Ambrozja z Aten o jednym oku, mimo iż wątpiła, uleczona została przez Asklepiosa podczas snu poprzez rozcięcie powieki i wlanie w jej oczodół jakiegoś leku. Zapłatą za uleczenie wątpiącej miał być z rozkazu boga srebrny posążek świni ${ }^{56}$.

Młodzieńca o imieniu Julian, św. Cyrus i Jan zmusili do porzucenia herezji poprzez sprawianie mu fizycznego bólu ${ }^{57}$, natomiast pewien trędowaty nie został uleczony, ponieważ nie wypełniał zbyt gorliwie poleceń świętych ${ }^{58}$. Nie-

\footnotetext{
${ }^{50}$ Por. Miracula S. Theclae 8, ed. Dagron (1987).

51 Por. Miracula Aesculapii 43.

52 Ibidem 25.

53 Ibidem 41.

${ }^{54}$ Por. Miracula SS. Cyri et Joannis 26.

55 Por. Miracula Aesculapi 3.

56 Ibidem 4.

57 Por. Miracula SS. Cyri et Johannis 12.

58 Ibidem 13.
} 
jaki Nemesios, chrześcijanin, za uprawianie astrologii ukarany został utratą wzroku i nie odzyskał go nawet po porzuceniu wróżbiarstwa. Jedyne co zyskał, to możliwość leczenia innych ludzi dotkniętych ślepotą ${ }^{59}$. Pewien lekarz z Aleksandrii, Gerios, ośmielił się twierdzić, że święci leczą według zasad sformułowanych przez Hippokratesa i Galena, oraz potajemnie czcił starych bogów. Kiedy sam zaniemógł, a lekarstwa nie skutkowały, udał się po pomoc do świętych. Święci zaś aż trzykrotnie zmieniali - na coraz cięższą - pokutę nałożoną zdumionemu lekarzowi. Wreszcie osiodłany jak osioł, z dzwonkiem u szyi, miał być prowadzony za uzdę przez jednego z własnych sług w samo południe po terenie sanktuarium, a przy tym wołać: „Jestem dureń i szaleniec”. Cierpiąc upokorzenie uwierzył, że święci leczą tylko z Bożego natchnienia, i wyzdrowiał ${ }^{60}$. Inny sparaliżowany poganin Agapios, który szukał ratunku u świętych i przyjął Eucharystię, ukarany został opętaniem przez złego ducha i zmarł w męczarniach w drodze do Aleksandrii ${ }^{61}$.

Śmiercią karała także św. Tekla: Marianos, biskup Tarsu, po tym jak poróżnił się z biskupem Seleucji, zabronił swoim wiernym udawać się na doroczne uroczystości obchodzone w jej sanktuarium. Św. Tekla ukarała go śmiercią, która nastąpiła w ciągu kilku dni. Aby nikt jednak nie miał wątpliwości, kto stoi za śmiercią krnąbrnego biskupa, święta objawiła się wcześniej pewnemu człowiekowi zapowiadając, że Marianos wkrótce zostanie ukarany ${ }^{62}$. R. Wiśniewski zauważył, że w przypadku tego cudu św. Tekli trudno oprzeć się wrażeniu, że dysponuje ona całkowicie autonomiczną mocą taumaturgiczną, a tego rodzaju praktyka nie jest zgodna z przeświadczeniem, że cud jest wyłącznie dziełem Boga. Prawda o właściwym autorstwie cudów była bardzo często podkreślana w żywotach świętych, co samo w sobie jest dowodem na to, że nie była ona dla wszystkich oczywista ${ }^{63}$. Inny z cudów św. Tekli dowodzi, jak wielkiemu rozmyciu uległa granica pomiędzy cudami pogańskimi i chrześcijańskimi; zawiera on bowiem zalecenie, żeby chory owinął talię dziecka wełną, którą później powinien spalić, a popiół dodać do zwykłego swojego lekarstwa ${ }^{64}$.

Niewątpliwie podobieństwa pomiędzy cudami Asklepiosa i anargyroi wynikały z jednakowej u pogan i chrześcijan wiary w boską ingerencję w bieg

${ }^{59}$ Ibidem 28.

${ }^{60}$ Ibidem, 30; cud ten można uznać za oddający stosunek medycyny świątynnej do praktyki lekarskiej; także w tym aspekcie opisy cudów stanowią źródło do historii późnoantycznej medycyny, por. H.J. Magoulias, The Lives of the Saints as Sources of Data for the History of Byzantine Medicine in the Sixth and Seventh Centuries, BZ 57(1964) 127-150.

${ }^{61}$ Por. Miracula SS. Cyri et Joannis 32.

62 Por. Miracula S. Theclae 29.

${ }^{63}$ R. Wiśniewski, Cuda i świętość, w: Chrześcijaństwo u schytku starożytności. Studia źródłoznawcze, red. T. Derda i E. Wipszycka, Warszawa 1997, ss. 283 i 294.

${ }^{64}$ Por. Miracula S. Theclae 11. 
spraw ludzkich, a ich podłożem było niezmienne pragnienie wyzwolenia się od dolegliwości, chorób i nieszczęść nękających ludzi różnych społeczności, kultur i epok. Swoją popularnością świadczą one pośrednio o długim trwaniu i o atrakcyjności uzdrowicielskiego kultu Asklepiosa oraz jego roli jako elementu pozwalającego na łatwiejsze porzucenie kultu starych bogów; stanowiąc zaś niezwykłą ilustrację cech charakterystycznych ówczesnej chrześcijańskiej mentalności i wrażliwości religijnej, nie dają podstaw do negowania jej oryginalności.

\section{DAS EINDRINGEN DER HEIDNISCHEN KULTE IN DAS CHRISTENTUM AM BEISPIEL DER KULTE VON GOTT ASKLEPIOS UND DEN HEILIGEN ANARGYROI}

(Zusammenfassung)

Es fällt auf, daß die Heiligen auf die gleiche Art und Weise Menschen von Krankheiten heilten wie der heidnische Gott Asklepios. Die Inkubation als heidnisches Ritual war im Kult von Anargyroi ('ohne Silber') anwesend. Ernst Lucius hat festgestellt, daß der Kult von Asklepios durch den von Kosmas und Damian ersetzt wurde. Lucius hat an Aigai gedacht, wo zuerst der göttliche Arzt und dann Anargyroi Kosmas und Damian verehrt wurden. Ludwig Deubner war mit Lucius nicht einverstanden, weil er Acta Martyrii, die von Kosmas und Damian handelten, in Frage stellte. Heutzutage stimmt man nicht mit allen Deubners Hypothesen überein. Man kann nicht vergessen, daß in Asklepieion in Aigai der Gottmensch Apollonios von Tiana verehrt wurde. Dieses Heiligtum wurde zerstört, als der Kult von Kosmas und Damian entstand. Das Eindringen der heidnischen Rituale in das Christentum war für die altertümliche Mentalität charakteristisch.

Übers. Katarzyna Kotowiecka-Dyrcz 